\title{
Pathophysiology and Risk Factors for Cholelithiasis in Patients with Crohn's Disease
}

\author{
I. STURDIK ${ }^{1}$, A. KRAJCOVICOVA ${ }^{1}$, Y. JALALI ${ }^{1}$, M. ADAMCOVA ${ }^{1}$, M. TKACIK ${ }^{1}$, \\ J. SEKAC, T. KOLLER ${ }^{1}$, M. HUORKA ${ }^{1}$, J. PAYER, T. HLAVATY ${ }^{1}$ \\ ${ }^{1} 5$ th Department of Internal Medicine, Faculty of Medicine, Comenius University Bratislava, \\ University Hospital Bratislava, Slovak Republic
}

Received June 18, 2019

Accepted September 23, 2019

\begin{abstract}
Summary
Cholelithiasis is more common in patients with Crohn's disease (CD) than in the healthy population. The aim here was to examine risk factors for cholelithiasis in a cohort of $C D$ patients and to compare the prevalence of cholelithiasis in a cohort of $C D$ patients with that in a control group. This was a single-center retrospective case-control study. The cohort comprised all consecutive $C D$ patients who underwent abdominal ultrasound from January 2007 to January 2018. The control group comprised age- and gender-matched non-CD patients referred for upper gastrointestinal tract dyspepsia. The study included $238 \mathrm{CD}$ patients and 238 controls. The prevalence of cholelithiasis in the $\mathrm{CD}$ and control groups was $12.6 \%$ and $9.2 \%$, respectively (risk ratio $(R R), 1.36 ; p=0.24$ ). Univariate analysis revealed that cholelithiasis was associated with multiple risk factors. Multivariate analysis identified age (OR, 1.077; $95 \%$ $\mathrm{CI}, 1.043-1.112 ; \mathrm{p}<0.001)$ and receipt of parenteral nutrition (OR, 1.812; $95 \% \mathrm{CI}, 1.131-2.903 ; \mathrm{p}=0.013$ ) as independent risk factors for cholelithiasis in $C D$ patients. The prevalence of cholelithiasis in $C D$ patients was higher than that in the control group; however, the difference was not statistically significant. Age and receipt of parenteral nutrition were independent risk factors for cholelithiasis in $C D$ patients.
\end{abstract}

\section{Key words}

Cholelithiasis • Crohn's disease • Prevalence • Risk factors

\section{Corresponding author}

I. Sturdik, $5^{\text {th }}$ Department of Internal Medicine, Medical Faculty, Comenius University and University Hospital, Ruzinovska 6, 826 06 Bratislava, Slovak Republic. E-mail: igor.sturdik@gmail.com

\section{Introduction}

Over the last 50 years, several studies (Heaton and Read 1969, Cohen et al. 1971, Baker et al. 1974, Hill et al. 1975, Whorwell et al. 1984, Andersson et al. 1987, Kangas et al. 1990, Lorusso et al. 1990, Hutchinson et al. 1994, Lapidus et al. 1999, Fraquelli et al. 2001, Bargiggia et al. 2003, Kratzer et al. 2005, Parente et al. 2007, Fagagnini and Heinrich 2017) and two metaanalyses (Gizard et al. 2014, Zhang et al. 2015) have reported increased prevalence of cholelithiasis in patients with inflammatory bowel disease (IBD). Reviews of cholecystography and abdominal ultrasound studies show that the prevalence of cholelithiasis in patients with Crohn's disease (CD) is between $11 \%$ and $46 \%$. Unfortunately, some of these studies did not have control groups. In the general population the prevalence of cholelithiasis is between $10 \%$ and $15 \%$, it varies considerably depending on the presence or the absence of risk factors. Case-control studies of cholelithiasis in IBD suggest that the relative risk of developing cholelithiasis is 2- to 4-fold higher than that in the general population (Baker et al. 1974, Whorwell et al. 1984, Lorusso et al. 1990, Lapidus et al. 1999, Fraquelli et al. 2001, Bargiggia et al. 2003, Parente et al. 2007). These results were confirmed by the most recently published metaanalysis of five studies, which showed that the prevalence of cholelithiasis is significantly higher in $\mathrm{CD}$ patients than in the healthy population (odds ratio (OR), 2.05; $95 \%$ confidence interval $(\mathrm{CI}), 1.61-2.63 ; \mathrm{p}<0.0001)$ (Zhang et al. 2015). Lapidus et al. showed that $26 \%$ of $\mathrm{CD}$ patients had cholelithiasis, with no differences in prevalence due to age, gender, or extent of ileal resection (Lapidus et al. 1999). Other authors point out that localization of $\mathrm{CD}$ to the ileum or ileocolon, but not the colon, predetermines development of cholelithiasis 
(Baker et al. 1974, Hill et al. 1975, Whorwell et al. 1984, Andersson et al. 1987, Lorusso et al. 1990).

At present, knowledge about the prevalence of cholelithiasis in CD patients is somewhat limited because most published studies are old and there have been marked changes in clinical practice over the past 20 years; therefore, it is unclear which risk factors for cholelithiasis are specific to $\mathrm{CD}$ patients.

The aim of this study was to assess the risk factors for cholelithiasis in patients with $\mathrm{CD}$ and identify complications. We then examined the characteristics and prevalence of cholelithiasis in CD patients and compared them with those of a healthy control group.

\section{Methods}

\section{Study design}

This was a single-center retrospective case-control study conducted at the IBD Center, 5th Department of Internal Medicine, Bratislava. The study included all consecutive $\mathrm{CD}$ patients followed up at the IBD Center or admitted to the 5th Department of Internal Medicine. All patients underwent abdominal ultrasound between January 2007 and January 2018.

\section{Study cohort}

The study enrolled patients with $\mathrm{CD}$ confirmed by standard clinical, endoscopic, radiologic (X-ray), and histopathological criteria. Exclusion criteria were as follows: age $<18$ years and a diagnosis of liver cirrhosis confirmed by prior liver biopsy or by clinical, biochemical, and ultrasound examination. The following demographic and clinical data were obtained for each enrolled patient: age at the time of the last ultrasound, sex, body mass index (BMI), CD Montreal classification, $\mathrm{CD}$ duration, cholecystectomy, type and number of abdominal resections, extent of ileal resection, number of clinical relapses before a diagnosis of gallstones or the last negative ultrasound, number of corticosteroid therapies, number of hospitalizations for $\mathrm{CD}$ relapse or disease complications, total number of days in hospital, and number of times that a patient received parenteral nutrition during hospitalization.

\section{Control group}

The control group comprised all non-CD patients who underwent abdominal ultrasound for dyspepsia from 2007 to 2018. All ultrasound examinations (for patients and controls) were conducted by the same sonographer. The ultrasound characteristics noted were the same as for
CD patients. Each $\mathrm{CD}$ patient was matched to a non-CD patient by age ( \pm 5 years) and gender.

\section{Ultrasound examination}

Patients underwent abdominal ultrasound after overnight fasting. All examinations were performed by a single experienced sonographist using an Aloka machine (ProSound Alpha 7). Cholelithiasis was defined as the presence of echogenic structures with acoustic shadows within the visible gallbladder lumen or the hepatocholedochus duct; one or more echogenic structures in the gallbladder without a dorsal shadow (which could be confidently distinguished from gallbladder, Heister plica spiralis, or gallbladder polyps by multiplanar visualization); or a structure with echogenicity and a dorsal acoustic shadow in a gallbladder whose lumen was not sufficiently visualized. The following information was obtained from ultrasound records: the date of the last negative examination or the first time gallstones were visualized, the presence of cholelithiasis, the number of gallstones, the size of the largest stone, history of gallstones/clinical manifestations, and follow-up treatment after detection of cholelithiasis. Any complications related to bile stones after the primary diagnosis were noted (number of days since the ultrasound diagnosis of bile stones and treatment of complications).

\section{Statistical analyses}

Statistical tests were performed using SPSS 21.0 software. The distribution of individual characteristics was evaluated using simple descriptive statistics. Univariate analyses of risk factors were performed. The chi-square test was used to assess categorical variables (clinical characteristics of $\mathrm{CD}$; BMI category; abdominal resection and type, number, and extent; number of disease relapses; corticoid courses; hospitalization; and number of times that a patient received parenteral nutrition). The KolmogorovSmirnov test was used to assess normal distribution of continuous data (age, $\mathrm{CD}$ duration, and $\mathrm{BMI}$ ). Consequently, Student's t-test and the Mann-Whitney $\mathrm{U}$ test (nonparametric) were used to assess continuous variables. The $95 \% \mathrm{CI}$ and the level of statistical significance (p) were calculated for all results. A p value $<0.05$ was considered significant. Finally, multivariate analysis was performed using forward logistic regression analysis (cholelithiasis as a dependent variable).

\section{Results}

In total, data from $331 \mathrm{CD}$ patients were 
analyzed; of these, 238 patients underwent at least one abdominal ultrasound. The $238 \mathrm{CD}$ patients were matched to 238 non-CD controls. Demographic and clinical characteristics are shown in Table 1.

Table 1. Demographic and clinical characteristics

\begin{tabular}{|c|c|c|c|}
\hline \multicolumn{2}{|l|}{ Characteristics } & $\mathrm{CD}(\mathrm{N}=238)$ & Controls $(\mathrm{N}=\mathbf{2 3 8})$ \\
\hline \multicolumn{2}{|l|}{ Female (\%) } & $114(48)$ & $114(48)$ \\
\hline \multicolumn{2}{|l|}{ Age (years, mean $\pm S D)$} & $40.0 \pm 12.5$ & $39.9 \pm 12.4$ \\
\hline \multicolumn{2}{|l|}{$C D$ duration (months, mean $\pm S D$ ) } & $102.8 \pm 80.3$ & \\
\hline \multirow[t]{4}{*}{ CD location (\%) } & L1 & $86(36)$ & \\
\hline & $\mathrm{L} 2$ & $30(13)$ & \\
\hline & L3 & $122(51)$ & \\
\hline & L4 & $15(6)$ & \\
\hline \multirow[t]{4}{*}{ CD behavior (\%) } & B1 & $103(43)$ & \\
\hline & $\mathrm{B} 2$ & $75(32)$ & \\
\hline & B3 & $60(25)$ & \\
\hline & $\mathrm{p}$ & $59(25)$ & \\
\hline \multirow[t]{3}{*}{ Age at CD diagnosis (\%) } & A1 & $30(12)$ & \\
\hline & $\mathrm{A} 2$ & $180(76)$ & \\
\hline & A3 & $28(12)$ & \\
\hline \multicolumn{2}{|l|}{ Inflammatory vs. aggressive CD (\%) } & 103 vs. 135 (43 vs. 57$)$ & \\
\hline \multicolumn{2}{|l|}{ Abdominal surgery (\%) } & $97(41)$ & \\
\hline \multirow[t]{3}{*}{ Number of surgeries (\%) } & 1 & $64(27)$ & \\
\hline & 2 & $17(7)$ & \\
\hline & $\geq 3$ & $16(7)$ & \\
\hline \multirow[t]{3}{*}{ Type of surgery (\%) } & ileal & $15(6)$ & \\
\hline & ileocecal/right-sided & $72(30)$ & \\
\hline & total colectomy & $10(4)$ & \\
\hline \multirow[t]{3}{*}{ Ileal resection (\%) } & $<30 \mathrm{~cm}$ & $62(26)$ & \\
\hline & $30-100 \mathrm{~cm}$ & $27(11)$ & \\
\hline & $>100 \mathrm{~cm}$ & $7(3)$ & \\
\hline \multirow[t]{3}{*}{ Clinical relapses (\%) } & 0 & $106(45)$ & \\
\hline & $1-2$ & 93 (39) & \\
\hline & $\geq 3$ & $39(16)$ & \\
\hline \multirow[t]{2}{*}{ Corticosteroid treatment (\%) } & $0-2$ & 209 (88) & \\
\hline & $\geq 3$ & $29(12)$ & \\
\hline \multirow[t]{3}{*}{ Number of hospitalizations (\%) } & $<2$ & $191(80)$ & \\
\hline & 2 & $20(9)$ & \\
\hline & $>2$ & $27(11)$ & \\
\hline \multirow{3}{*}{$\begin{array}{l}\text { Number of hospitalization days } \\
(\%)\end{array}$} & $<20$ & 189 (79) & \\
\hline & $20-39$ & $27(11)$ & \\
\hline & $\geq 40$ & $22(10)$ & \\
\hline \multirow{3}{*}{$\begin{array}{l}\text { Number of times that a patient } \\
\text { received parenteral nutrition (\%) }\end{array}$} & 0 & $156(66)$ & \\
\hline & 1 & $42(17)$ & \\
\hline & $\geq 2$ & $40(17)$ & \\
\hline
\end{tabular}

CD, Crohn's disease; N, absolute number; SD, standard deviation; Location L1: ileum; L2: colon; L3: ileocolon; L4: upper gastrointestinal tract; Behavior B1: inflammation; B2: stenosing; B3: penetrating; p, perianal disease; Age at diagnosis A1: < 17 years; A2: $17-40$ years; $A 3:>40$ years. 


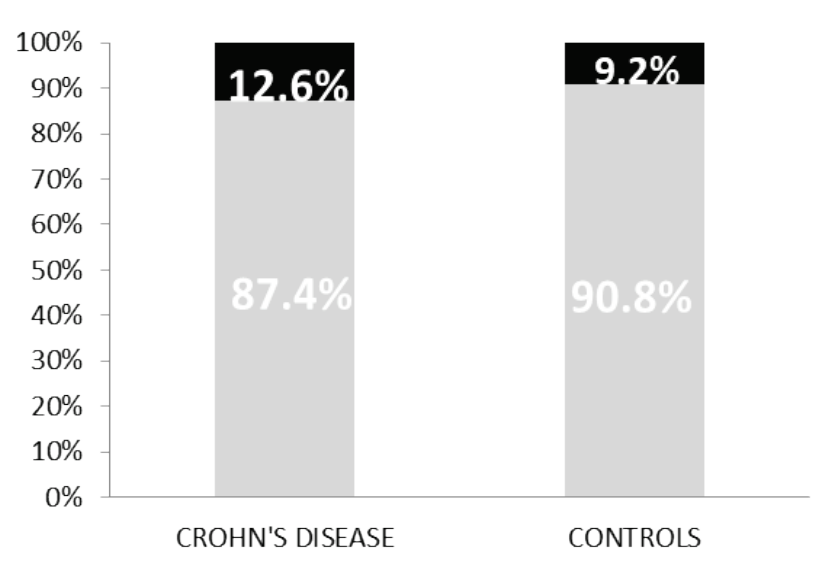

Fig. 1. Cholelithiasis in patients with Crohn's disease and controls. $p=0.24$, Cholelithiasis, $\square$ Noncholelithiasis

\section{Prevalence of cholelithiasis and its characteristics}

Cholelithiasis was present in 30/238 CD patients (12.6\%); of these, 26 had cholecystolithiasis, three had choledocholithiasis, and one had cholecystolithiasis and choledocholithiasis. In the control group, 22/238 patients $(9.2 \%)$ had cholelithiasis; of these, 21 had cholecystolithiasis and one had choledocholithiasis. The difference between the groups was not significant $(\mathrm{p}=0.24)$ (Fig. 1).

Almost half (14/30) of CD patients had a solitary stone, $26 \%(8 / 30)$ had two to five confirmed stones, and $26 \%(8 / 30)$ of patients had multiple small stones. Two-thirds (20/30) of patients were asymptomatic; the remaining ten $(33 \%)$ had clinical symptoms of cholelithiasis. Of these, eight had uncomplicated biliary colic with no signs of cholestasis or inflammation and two had cholestasis and inflammation. Overall, $17 \%$ (5/30) of patients required cholecystectomy, three with repeated biliary counts, one asymptomatic patient, and one with cholestasis. Endoscopic retrograde cholangiopancreatography (ERCP) was performed in one patient with cholangitis and obstructive jaundice. Only this patient experienced complications with respect to recurrence of cholestasis and inflammation; therefore, the patient underwent further ERCP sessions and an elective cholecystectomy is planned.

\section{Analyses of risk factors for cholelithiasis}

Univariate analysis revealed that age, age at the time of $\mathrm{CD}$ diagnosis, inflammatory versus aggressive (stricturing or perforating) $\mathrm{CD}, \mathrm{CD}$ duration, abdominal resection, number of intestinal resections, length of the resected ileum, number of corticoid courses, hospitalization, and number of times that a patient received parenteral nutrition were significantly associated with cholelithiasis in CD patients; therefore, these factors were entered into multivariate analysis (Table 2). Multivariate forward regression analysis identified two independent risk factors that increase the likelihood of cholelithiasis in $\mathrm{CD}$ patients: age (OR, 1.077; $95 \% \mathrm{CI}$, $1.043-1.112 ; \mathrm{p}<0.001)$ and number of times that a patient received parenteral nutrition (OR, 1.812; $95 \% \mathrm{CI}, 1.131-$ 2.903; $\mathrm{p}=0.013$ ).

\section{Discussion}

Several studies (Heaton and Read 1969, Cohen et al. 1971, Baker et al. 1974, Hill et al. 1975, Whorwell et al. 1984, Andersson et al. 1987, Kangas et al. 1990, Lorusso et al. 1990, Hutchinson et al. 1994, Lapidus et al. 1999, Fraquelli et al. 2001, Bargiggia et al. 2003, Kratzer et al. 2005, Parente et al. 2007, Fagagnini and Heinrich 2017) and two meta-analyses (Gizard et al. 2014, Zhang et al. 2015) published since the 1970s show that $\mathrm{CD}$ patients have an increased prevalence of cholelithiasis. The prevalence reported by these studies was between $8 \%$ and $46 \%$; 8 of the 15 studies examined patients' cohorts. Meta-analyses and studies with control groups reveal that the risk of cholelithiasis in $\mathrm{CD}$ patients is 2- to 4-fold higher than that in the general population. Here, we found that the prevalence of cholelithiasis in $\mathrm{CD}$ patients and controls was $12.6 \%$ and $9.2 \%$, respectively (Table 3). Although the number of CD patients with cholelithiasis was higher, the difference between the groups did not reach statistical significance $(p=0.24)$. The possible explanation for this is that the control group was made up of non-CD patients with dyspepsia, who underwent abdominal ultrasound; therefore, it was not a completely "healthy" population and the prevalence of cholelithiasis could have been higher in this group than in a truly "healthy" group.

Ten studies discussed risk factors for cholelithiasis in patients with CD (Baker et al. 1974, Whorwell et al. 1984, Lorusso et al. 1990, Hutchinson et al. 1994, Lapidus et al. 1999, Fraquelli et al. 2001, Bargiggia et al. 2003, Kratzer et al. 2005, Parente et al. 2007, Fagagnini and Heinrich 2017). The most common risk factor for gallstones was previous intestinal resection, which was evaluated by seven studies. Parente et al. showed that resection of $>30 \mathrm{~cm}$ of ileum was associated with cholelithiasis (OR, 7.03; $95 \%$ CI, 2.5619.3). Lapidus et al. showed that $48 \%$ (10/21) of patients who underwent at least three intestinal resections developed cholelithiasis compared with $20.7 \%$ (6/29) of those that did not have surgery $(\mathrm{p}<0.005)$. We also found 
Table 2. Analysis of cholelithiasis risk factors in patients with Crohn's disease

\begin{tabular}{|c|c|c|c|c|c|}
\hline \multicolumn{2}{|l|}{ Characteristics } & $\begin{array}{c}\text { Lithiasis } \\
\mathbf{N}=\mathbf{3 0}\end{array}$ & $\begin{array}{l}\text { No Lithiasis } \\
\quad \mathbf{N}=\mathbf{2 0 8}\end{array}$ & OR & $\mathbf{p}$ \\
\hline \multicolumn{2}{|l|}{ Female (\%) } & $15(50)$ & $99(48)$ & 0.61 & 0.805 \\
\hline \multicolumn{2}{|l|}{ Age (years, mean $\pm S D$ ) } & $51.5 \pm 15.0$ & $38.4 \pm 11.2$ & 3.121 & 0.0001 \\
\hline \multicolumn{2}{|l|}{$B M I$} & $25.6 \pm 5.8$ & $23.9 \pm 4.9$ & 0.395 & 0.075 \\
\hline \multicolumn{2}{|c|}{$C D$ duration (months, mean $\pm S D$ ) } & $95.4 \pm 88.7$ & $10.9 \pm 79.2$ & 1.54 & 0.604 \\
\hline \multirow[t]{4}{*}{ CD location (\%) } & L1 & $10(33)$ & $76(37)$ & 0.455 & 0.796 \\
\hline & L2 & $3(10)$ & $27(13)$ & & \\
\hline & L3 & $17(57)$ & $105(50)$ & & \\
\hline & L4 & 0 & $15(7)$ & & \\
\hline \multirow[t]{4}{*}{ CD behavior (\%) } & B1 & $7(23)$ & $96(46)$ & 5.727 & 0.057 \\
\hline & B2 & $12(40)$ & $63(30)$ & & \\
\hline & B3 & $11(37)$ & $49(24)$ & & \\
\hline & $\mathrm{p}$ & $4(13)$ & $55(26)$ & & \\
\hline \multirow[t]{3}{*}{ Age at CD diagnosis (\%) } & A1 & 0 & $30(14)$ & 18.265 & 0.0001 \\
\hline & A2 & $20(67)$ & $160(77)$ & & \\
\hline & A3 & $10(33)$ & $18(9)$ & & \\
\hline \multicolumn{2}{|c|}{ Inflammatory vs. aggressive CD (\%) } & $\begin{array}{c}7 \text { vs. } 23 \\
\text { (23 vs. } 77)\end{array}$ & $\begin{array}{l}96 \text { vs. } 112 \\
\text { (46 vs. } 4)\end{array}$ & 5.562 & 0.018 \\
\hline \multicolumn{2}{|l|}{ Abdominal surgery (\%) } & $18(60)$ & $79(38)$ & 5.265 & 0.022 \\
\hline \multirow{3}{*}{$\begin{array}{l}\text { Number of surgeries } \\
(\%)\end{array}$} & 1 & $9(30)$ & $55(26)$ & 7.528 & 0.001 \\
\hline & 2 & $6(20)$ & $11(5)$ & & \\
\hline & $\geq 3$ & $3(10)$ & $13(6)$ & & \\
\hline \multirow[t]{3}{*}{ Type of surgery (\%) } & ileal & $2(7)$ & $13(6)$ & 6.640 & 0.084 \\
\hline & ileocecal/right-sided & $15(50)$ & $57(27)$ & & \\
\hline & $\begin{array}{l}\text { hemicolectomy } \\
\text { total colectomy }\end{array}$ & $1(3)$ & $9(4)$ & & \\
\hline \multirow[t]{3}{*}{ Ileal resection (\%) } & $<30 \mathrm{~cm}$ & $9(30)$ & $53(26)$ & 8.399 & 0.038 \\
\hline & $30-100 \mathrm{~cm}$ & $7(23)$ & $20(10)$ & & \\
\hline & $>100 \mathrm{~cm}$ & $2(7)$ & $5(2)$ & & \\
\hline \multirow{3}{*}{ Clinical relapses (\%) } & 0 & $11(37)$ & $95(46)$ & 2.742 & 0.254 \\
\hline & $1-2$ & $11(37)$ & $82(40)$ & & \\
\hline & $\geq 3$ & $8(26)$ & $31(14)$ & & \\
\hline \multirow{2}{*}{$\begin{array}{l}\text { Corticosteroid } \\
\text { treatments (\%) }\end{array}$} & $0-2$ & $22(73)$ & $187(90)$ & 6.728 & 0.009 \\
\hline & $\geq 3$ & $8(27)$ & $21(10)$ & & \\
\hline \multirow{3}{*}{$\begin{array}{l}\text { Number of } \\
\text { hospitalizations (\%) }\end{array}$} & $<2$ & $18(60)$ & $173(83)$ & 8.893 & 0.012 \\
\hline & 2 & $5(17)$ & $15(7)$ & & \\
\hline & $>2$ & $7(23)$ & $20(10)$ & & \\
\hline \multirow{3}{*}{$\begin{array}{l}\text { Number of } \\
\text { hospitalization days } \\
\text { (\%) }\end{array}$} & $<20$ & $20(67)$ & $169(81)$ & 5.118 & 0.077 \\
\hline & $20-39$ & $4(13)$ & $23(11)$ & & \\
\hline & $\geq 40$ & $6(20)$ & $16(8)$ & & \\
\hline \multirow{3}{*}{$\begin{array}{l}\text { Number of times that } \\
\text { a patient received } \\
\text { parenteral nutrition (\%) }\end{array}$} & 0 & $13(43)$ & $143(69)$ & 8.792 & 0.012 \\
\hline & 1 & $7(23)$ & $35(17)$ & & \\
\hline & $\geq 2$ & $10(34)$ & $30(14)$ & & \\
\hline
\end{tabular}

CD, Crohn's disease; N, absolute number; SD, standard deviation; Location L1: ileum; L2: colon; L3: ileocolon; L4: upper gastrointestinal tract; Behavior B1: inflammation; B2: stenosing; B3: penetrating; p, perianal disease; Age at diagnosis A1: <17 years; A2: $17-40$ years; $A 3:>40$ years. 
that previous intestinal resection, absolute number of resections, and the extent of ileal resection were associated with a higher prevalence of cholelithiasis in those with CD.

Other identified risk factors were CD location (Lorusso et al. 1990, Fraquelli et al. 2001, Parente et al. 2007), CD duration (Baker et al. 1974, Hutchinson et al. 1994, Parente et al. 2007, Fagagnini and Heinrich 2017), and age at the time of CD diagnosis (Fagagnini and Heinrich 2017). Patients with CD affecting the ileocecal or ileocolonic area had a 2-fold greater risk of developing cholelithiasis than patients with only small intestine involvement. The incidence of cholelithiasis was almost $20 \%$ when the disease lasted for more than 15 years (Parente et al. 2007). Studies published to date did not examine the effect of CD behavior on the prevalence of cholelithiasis. Here, we found that age at the time of $\mathrm{CD}$ diagnosis was significantly associated with the prevalence of cholelithiasis. A particular trend of significance was also seen with respect to $C D$ behavior. Neither CD location nor CD duration was a risk factor for gallstones.

Table 3. Table summarizing the prevalence of cholelithiasis reported from previous published studies

\begin{tabular}{|c|c|c|c|}
\hline \multirow[t]{2}{*}{ Authors of study } & \multirow[t]{2}{*}{ IBD Type } & \multicolumn{2}{|c|}{ Prevalence of cholelithiasis (\%) } \\
\hline & & IBD & Controls \\
\hline Heaton and Read & CD terminal ileum & 30 & \\
\hline Cohen et al. & CD terminal ileum & 34 & \\
\hline \multirow[t]{5}{*}{ Baker et al. } & $\mathrm{CD}$ & & \\
\hline & ileocolitis & 31 & 12 \\
\hline & terminal ileitis & 27 & 12 \\
\hline & colitis & 11 & 12 \\
\hline & $\mathrm{UC}$ & 8 & 12 \\
\hline Hill et al. & CD ileal resection & 25 & \\
\hline Whorwell et al. & CD terminal ileum & 38 & 8 \\
\hline Andersson et al. & CD ileum & 17 & \\
\hline \multirow[t]{2}{*}{ Lorusso et al. } & $\mathrm{CD}$ & 14 & 10 \\
\hline & $\mathrm{UC}$ & 9 & 10 \\
\hline Kangas et al. & CD ileitis & 24 & 15 \\
\hline \multirow[t]{2}{*}{ Hutchinson et al. } & CD ileum & 46 & 5 \\
\hline & colon & 25 & 5 \\
\hline Lapidus et al. & $\mathrm{CD}$ & 30 & 15 \\
\hline \multirow[t]{2}{*}{ Kratzer et al. } & CD ileum & 6 & \\
\hline & colon & 6 & \\
\hline \multirow[t]{4}{*}{ Fraquelli et al. } & CD ileum & 18 & \\
\hline & ileocecal & 39 & \\
\hline & ileum and colon & 23 & \\
\hline & colon & 30 & \\
\hline \multirow[t]{2}{*}{ Parente et al. } & $\mathrm{CD}$ & 10 & 5 \\
\hline & $\mathrm{UC}$ & 7 & 10 \\
\hline \multirow[t]{2}{*}{ Bargiggia et al. } & $\mathrm{CD}$ & 13 & 6 \\
\hline & $\mathrm{UC}$ & 8 & 6 \\
\hline \multirow[t]{2}{*}{ Fagagnini et al. } & $\mathrm{CD}$ & 8 & \\
\hline & $\mathrm{UC}$ & 4 & \\
\hline Sturdik et al. & $\mathrm{CD}$ & 13 & 9 \\
\hline
\end{tabular}

$\mathrm{CD}$, Crohn's disease; UC, ulcerative colitis; IBD, inflammatory bowel disease. 
We also examined hospitalization and number of times that a patient received parenteral nutrition, as these parameters affect gallbladder motility and thus development of cholelithiasis. The number of hospitalizations and the number of times that a patient received parenteral nutrition were associated with cholelithiasis; however, multivariate analysis identified only the number of times that a patient received parenteral nutrition as an independent risk factor for cholelithiasis in $\mathrm{CD}$ patients. $\mathrm{CD}$ patients who received more than one parenteral nutrition administration had a 3-fold higher prevalence of cholelithiasis than those who never received parenteral nutrition (Fig. 2). Parente et al. showed that patients hospitalized more than three times and those with a total length of hospital stay of more than 40 days had a 20 -fold increased risk of developing cholelithiasis compared with those who were hospitalized less frequently or for shorter times. No study published to date assessed the effect of biological therapy on the development of cholelithiasis in $\mathrm{CD}$ patients. It can be assumed that in some selected CD patients early and optimised biological therapy can achieve good control of disease, it can prevent CD complications, clinical relapses, need for abdominal surgeries, corticosteroid treatments, hospitalizations and so cholelithiasis is less frequent.

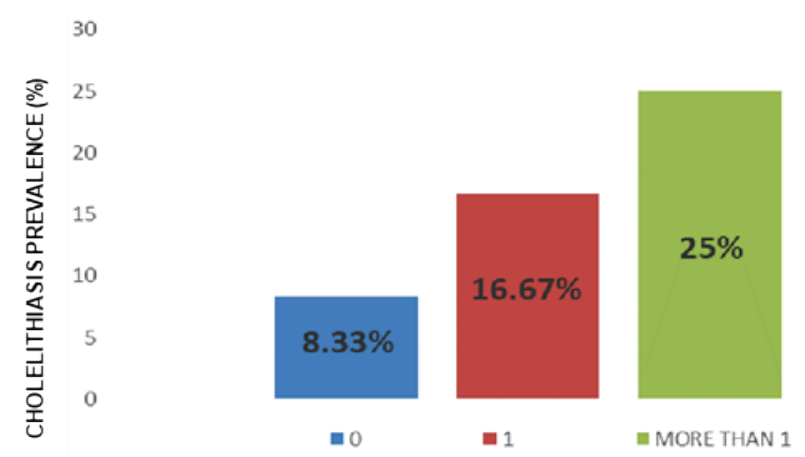

Fig. 2. Prevalence of cholelithiasis in patients with Crohn's disease according to the number of times a patient received parenteral nutrition.

Cholesterol gallstones dominate the standard European population, and age, gender and obesity are the most critical risk factors underlying development of cholelithiasis. In the population of $\mathrm{CD}$ patients studied herein, only age was an independent risk factor. We confirmed that the risk of cholelithiasis increases significantly with age. The prevalence of cholelithiasis in CD patients increased gradually from $5.88 \%$ in those under 30 years to $28.57 \%$ in patients older than 50 years, representing an almost five times higher prevalence in the latter group (Fig. 3).

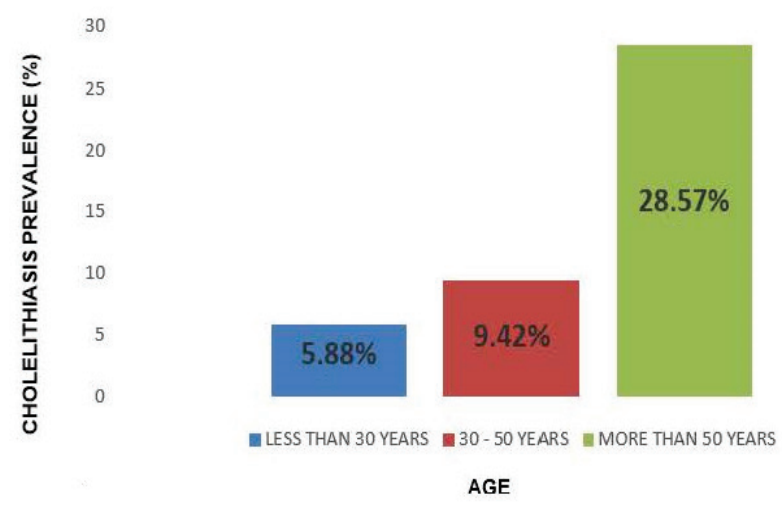

Fig. 3. Prevalence of cholelithiasis in patients with Crohn's disease according to age.

In addition, univariate analyses identified several potential risk factors associated with cholelithiasis. However, multivariate analysis confirmed only age and the number of times that a patient received parenteral nutrition as risk factors. This may be because most of the evaluated variables reflect the severity of the disease and correlate with each other; therefore, they did not reach statistical significance in multivariate analysis.

Based on our results, we suggest that cholelithiasis develops in $\mathrm{CD}$ patients due to a combination of factors that are partly related to $C D$ itself (disease location, ileal resection), partly related to CD morbidity (hospitalization, relapse rate, total number of times that a patient received parenteral nutrition), and partly CD-independent.

In the past, the pathogenesis of cholelithiasis in CD patients was attributed to disorders of the enterohepatic circulation of bile salts (Cohen et al. 1971, Dowling et al. 1972). It was believed that CD located in the ileum, or resection of the ileum, resulted in loss of bile acids from the intestine, thereby reducing the total bile acid supply in the body; this was followed by supersaturation of the bile with cholesterol. This idea was accepted as a probable explanation for development of cholelithiasis; however, recent studies reached other conclusions. For example, cholesterol saturation of the bile in $\mathrm{CD}$ patients is not increased after ileal resection; rather, it is reduced or within the normal range (Lapidus and Einarsson 1998).

In western populations, $90 \%$ of gallstones are cholesterol-based and $10 \%$ are pigment-based; however, there is evidence that $\mathrm{CD}$ patients develop pigment-based rather than cholesterol-based gallstones. Brink et al. performed bile analysis and found that bilirubin levels in patients with $\mathrm{CD}$ localized in the ileum and/or in $\mathrm{CD}$ patients with ileal resection were significantly higher 
than those in patients with colonic CD (Brink et al. 1999). This suggests that increased amounts of conjugated bilirubin reach the colon, where intestinal bacterial glucuronidases hydrolyze it to form unconjugated bilirubin. Unconjugated bilirubin is absorbed by the liver, where it is reconjugated and excreted into the bile. This bilirubin may precipitate as calcium salts, triggering formation of the gallstones even in the presence of bile stasis or gallbladder hypomotility (Masclee and Vu 2003, Vitek and Carey 2003).

Several studies have evaluated the interdigestive and digestive motility of the gallbladder in IBD patients (Murray et al. 1992, Salemans et al. 1995, Maurer et al. 1996, Damiao et al. 1997, Damiao et al. 1997, Vu et al. 2000). Gallbladder volume in fasting CD patients was not significantly different from that in a control group. However, when $\mathrm{Vu}$ et al. (2000) analyzed a subgroup of $\mathrm{CD}$ patients with respect to disease localization and previous ileal resection, they observed smaller fasting gallbladder volumes in those with colonic $\mathrm{CD}$ and in those that had undergone ileocecal resection.

\section{Study strengths and limitations}

We believe that the main strength of this study is that we assessed the actual relative risk of cholelithiasis in patients with mild to severe CD activity. Also, it was essential to establish a control group that included patients of similar age, gender, and geographical location to minimize the impact of demographic, environmental, and genetic factors that play an essential role in development of gallstones. One limitation is that the $\mathrm{CD}$ group did not match the control group with respect to BMI, which is a significant risk factor for development of cholelithiasis in the general population. Second, although the control group comprised non-CD patients, they were not wholly "healthy" individuals because they suffered dyspepsia, for which they had undergone an abdominal ultrasound.

\section{Conclusion}

Current international and Slovak guidelines do not include specific precautionary measures for cholelithiasis. Nevertheless, identification of patients at high risk of cholelithiasis (e.g., those that have undergone extensive ileal resection and/or multiple hospitalizations) appears to be important for primary prevention. Based on current knowledge, it seems appropriate to ensure that the number of times a patient receives parenteral nutrition is kept to a minimum to reduce the risk of cholelithiasis. If it is necessary to administer parenteral nutrition for a longer period, cholecystokinin and parenteral amino acid solutions should be added to the treatment, thereby reducing the risk of sludge and gallstone formation. There is the potential for long-term administration of ursodeoxycholic acid in high-risk CD patients. So far, placebo-controlled studies show the benefit of ursodeoxycholic acid administration with respect to primary prevention in those that are fasting or experiencing moderate weight loss (maximum weight loss of $1.5 \mathrm{~kg}$ per week). However, these studies did not demonstrate the benefit of administering ursodeoxycholic acid to those with symptomatic or asymptomatic cholelithiasis, or in situations other than rapid weight loss (Venneman and van Erpecum 2006).

\section{Conflict of Interest}

There is no conflict of interest.

\section{Acknowledgements}

Ethical considerations: Although this was a retrospective study, all patients consented to the use of their data. The study was approved by the local ethical committee.

\section{References}

ANDERSSON H, BOSAEUS I, FASTH S, HELLBERG R, HULTÉN L: Cholelithiasis and urolithiasis in Crohn's disease. Scand J Gastroenterol 22: 253-256, 1987.

BAKER AL, KAPLAN MM, NORTON RA, PATTERSON JF: Gallstones in inflammatory bowel disease. Am J Dig Dis 19: 109-112, 1974

BARGIGGIA S, MACONI G, ELLI M, MOLTENI P, ARDIZZONE S, PARENTE F, TODARO I, GRECO S, MANZIONNA G, BIANCHI PORRO G: Sonographic prevalence of liver steatosis and biliary tract stones in patients with inflammatory bowel disease: study of 511 subjects at a single center. $J$ Clin Gastroenterol 36: 417-420, 2003.

BRINK MA, SLORS JF, KEULEMANS YC, MOK KS, DE WAART DR, CAREY MC, GROEN AK, TYTGAT GN: Enterohepatic cycling of bilirubin: a putative mechanism for pigment gallstone formation in ileal Crohn's disease. Gastroenterology 116: 1420-1427, 1999. 
COHEN S, KPPLAN M, GOTTLIEB L, PATTERSON J: Liver disease and gallstones in regional enteritis. Gastroenterology 60: 237-245, 1971.

DAMIAO AO, SIPAHI AM, VEZOZZO DP, GONCALVES PL, HABR-GAMA A, TEIXEIRA MG, FUKUSHIMA JT, LAUDANNA AA: Effects of colectomy on gallbladder motility in patients with ulcerative colitis. Dig Dis Sci 42: 259-264, 1997.

DAMIAO AO, SIPAHI AM, VEZOZZO DP, GONCALVES PL, FUKUI P, LAUDANNA AA: Gallbladder hypokinesia in Crohn's disease. Digestion 58: 458-463, 1997.

DOWLING RH, BELL GD, WHITE J: Lithogenic bile in patients with ileal dysfunction. Gut 13: 415-420, 1972.

FAGAGNINI S, HEINRICH H: Risk factors for gallstones and kidney stones in a cohort of patients with inflammatory bowel diseases. PLoS One 12: e0185193, 2017.

FRAQUELLI M, LOSCO A, VISENTIN S, CESANA BM, POMETTA R, COLLI A, CONTE D: Gallstone disease and related risk factors in patients with Crohn disease: analysis of 330 consecutive cases. Arch Intern Med 161: 2201-2204, 2001.

GIZARD E, FORD AC, BRONOWICKI JP, PEYRIN-BIROULET L: Systematic review: The epidemiology of the hepatobiliary manifestations in patients with inflammatory bowel disease. Aliment Pharmacol Ther 40: 3-15, 2014.

HEATON KW, READ AE: Gall stones in patients with disorders of the terminal ileum and disturbed bile salt metabolism. Br Med J 3: 494-496, 1969.

HILL GL, MAIR WS, GOLIGHER JC: Gallstones after ileostomy and ileal resection. Gut 16: 932-936, 1975.

HUTCHINSON R, TYRRELL PN, KUMAR D, DUNN JA, LI JK, ALLAN RN: Pathogenesis of gall stones in Crohn's disease: an alternative explanation. Gut 35: 94-97, 1994.

KANGAS E, LEHMUSTO P, MATIKAINEN M: Gallstones in Crohn's disease. Hepatogastroenterology 37: 83-84, 1990.

KRATZER W, HAENLE MM, MASON RA, VON TIRPITZ C, KAECHELE V: Prevalence of cholelithiasis in patients with chronic inflammatory bowel disease. World J Gastroenterol 11: 6170-6175, 2005.

LAPIDUS A, BANGSTAD M, ASTROM M, MUHRBECK O: The prevalence of gallstone disease in a defined cohort of patients with Crohn's disease. Am J Gastroenterol 94: 1261-1266, 1999.

LAPIDUS A, EINARSSON C: Bile composition in patients with ileal resection due to Crohn's disease. Inflamm Bowel Dis 4: 89-94, 1998.

LORUSSO D, LEO S, MOSSA A, MISCIAGNA G, GUERRA V: Cholelithiasis in inflammatory bowel disease. A case-control study. Dis Colon Rectum 33: 791-794, 1990.

MASCLEE AA, VU MK: Gallbladder motility in inflammatory bowel diseases. Dig Liver Dis 35 (Suppl. 3): 35-38, 2003.

MAURER P, HAAG K, ROTH M, KUDER C, SCHOLMERICH J: No evidence for abnormal gallbladder emptying in Crohn's disease. Hepatogastroenterology 43: 807-812, 1996.

MURRAY FE, MCNICHOLAS M, STACK W, O'DONOGHUE: Impaired fatty-meal-stimulated gallbladder contractility in patients with Crohn's disease. Clin Sci 83: 689-693, 1992.

PARENTE F, PASTORE L, BARGIGGIA S, CUCINO C, GRECO S, MOLTENI M, ARDIZZONE S, PORRO GP, SAMPIETRO GM, GIORGI R, MORETTI R, GALLUS S: Incidence and risk factors for gallstones in patients with inflammatory bowel disease: a large case-control study. Hepatology 45: 1267-1274, 2007.

SALEMANS J, THIMISTER P, HOPMAN W, KUIJPERS H, ROSENBUSCH G, NAGENGAST F, JANSEN J: Plasma cholecystokinin levels and gallbladder volumes after proctocolectomy with ileal pouch-anal anastomosis. Surgery 117: 705-711, 1995.

VENNEMAN NG, VAN ERPECUM KJ: Gallstone disease: Primary and secondary prevention. Best Pract Res Clin Gastroenterol 20: 1063-1073, 2006.

VITEK L, CAREY MC: Enterohepatic cycling of bilirubin as a cause of 'black' pigment gallstones in adult life. Eur J Clin Invest 33: 799-810, 2003.

VU MK, GIELKENS HA, VAN HOGEZAND RA. VAN OOSTAYEN JA, LAMERS CB, MASCLEE AA: Gallbladder motility in Crohn disease: influence of disease localization and bowel resection. Scand J Gastroenterol 35: 1157-1162, 2000. 
WHORWELL PJ, HAWKINS R, DEWBURY K, WRIGHT R: Ultrasound survey of gallstones and other hepatobiliary disorders in patients with Crohn's disease. Dig Dis Sci 29: 930-933, 1984.

ZHANG FM, XU CF, SHAN GD, CHEN HT, XU GQ: Is gallstone disease associated with inflammatory bowel diseases? A meta-analysis. J Dig Dis 16: 634-641, 2015. 